Check for updates

Cite this: RSC Adv., 2017, 7, 47448

Received 8th August 2017

Accepted 5th October 2017

DOI: $10.1039 / c 7 r a 08759 d$

rsc.li/rsc-advances

\section{Preparation of N, P co-doped activated carbons derived from honeycomb as an electrode material for supercapacitors $\uparrow$}

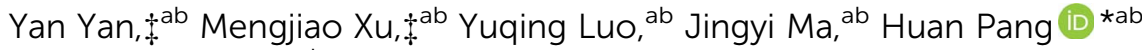 \\ and Huaiguo Xue ${ }^{\star a b}$
}

In this study, we use N, P co-doped activated carbon prepared from honeycomb as an electrode material for supercapacitors. The texture characteristics of the materials are determined by using nitrogen adsorption analysis. Thermal properties, the crystal structure/phase composition and surface element composition are observed by TGA, XRD and XPS, respectively. The morphologies of the samples have been characterized via FESEM and HRTEM. In order to further study the surface functional groups and degree of graphitization (conductivity) of the samples, we have conducted FTIR and Raman spectra tests. The electrochemical performance is investigated using an electrochemical workstation. In $3 \mathrm{M} \mathrm{KOH}$ electrolyte solution, $\mathrm{N}, \mathrm{P}$ co-doped activated carbon shows an excellent electrochemical performance with good high specific capacitance $\left(375.0 \mathrm{~F} \mathrm{~g}^{-1}\right.$ at $0.5 \mathrm{~A} \mathrm{~g}^{-1}$ ) and remarkable rate capability $\left(315.1 \mathrm{~F} \mathrm{~g}^{-1}\right.$ at even $10 \mathrm{~A} \mathrm{~g}^{-1}$ ). It also shows excellent cycle performance, after 10000 charge and discharge cycles the specific capacitance was still maintained as the original $98.7 \%$. In addition, we fabricate a symmetric supercapacitor device to further to study the electrochemical performance of N, P co-doped activated carbons. At a current density of $1.0 \mathrm{~A} \mathrm{~g}^{-1}$, the symmetric supercapacitor exhibits an excellent cycle performance in that the specific capacitance was maintained as the original $98.1 \%$ after 10000 chargedischarge cycles. The symmetric supercapacitor gives a maximum energy density of $27.6 \mathrm{~W} \mathrm{~h} \mathrm{~kg}^{-1}$ at a power density of $398.4 \mathrm{~W} \mathrm{~kg}^{-1}$.

\section{Introduction}

Today, global energy consumption is growing strikingly owing to the increasing energy demand..$^{1-5}$ To tackle this urgent environmental problem the key is to develop renewable clean energy. Energy storage devices such as fuel cells, second generation lithium batteries and supercapacitors have shown great promise in enabling the utilization of energy generated from novel sources such as solar and wind. ${ }^{6,7}$ Supercapacitors are promising energy-storage devices with significant superiorities such as high power density, fast charge-discharge rate and long cycling life, which have numerous applications in electric devices, modern communication, aerospace and defense. $^{8-12}$ However, low energy density limits their wide application. The key to the performance and cost of the

\footnotetext{
${ }^{a}$ School of Chemistry and Chemical Engineering, Yangzhou University, Yangzhou, 225002, Jiangsu, P. R. China. E-mail: huanpangchem@hotmail.com; panghuan@ yzu.edu.cn; chhgxue@yzu.edu.cn

${ }^{b}$ Institute for Innovative Materials and Energy, Yangzhou University, Yangzhou, 225002, Jiangsu, P. R. China

$\dagger$ Electronic supplementary information (ESI) available. See DOI: $10.1039 / \mathrm{c} 7 \mathrm{ra08759d}$

\$ These authors contributed equally to this paper.
}

supercapacitors the performance of the electrode, so the research on it mainly focuses on the research of the electrode. ${ }^{13-15}$

Activated carbons (ACs), the materials having research history exceeding several decade constitute the longest known class of porous carbon materials not only with apparent surface area and micropore volume but also with inhomogeneous pore distribution. ${ }^{16-19}$ Due to its high theoretical capacitance, ACs are presently the most widely used electrode materials for supercapacitors. Although ACs have high surface areas for charge storage the charges stored on the surface of carbon are unfortunately limited in the range of $10-50 \mu \mathrm{F} \mathrm{cm}^{-2}$ because of its poor conductivity. ${ }^{20-22}$

In order to match the increasing energy and to avoid resource depletion and environmental pollution, there is a demand for the development of high-performance, low cost and environmental-friendly energy storage devices. Suitable materials become the essential ingredients. ${ }^{23-30}$ Because raw materials from coal, asphalt and coke prepared for ACs are not renewable and expensive, research is now focused on finding low-cost, resource-rich and renewable natural biomass carbon sources (including willow catkin, ${ }^{31}$ fish scale, ${ }^{32}$ waste boatfruited sterculia seed, ${ }^{33}$ Artemia cyst shellalgae, ${ }^{34}$ silk, ${ }^{35}$ Ailanthus altissima ${ }^{36}$ and Borassus flabellifer flower, ${ }^{37}$ etc.) to produce 
AC which is a very promising candidate as the supercapacitor electrode. The honeycomb is the nest of bee which is built by bee workers using wax produced via their own wax glands. Beekeeping is widely distributed in our country. In the process of honey collection and processing, the honeycomb is often discarded as waste, so it has a broad application prospect to recycle.

Recent studies have shown that the surface chemistry of activated carbon materials is also an important factor that affects the specific capacitance of supercapacitors. Heteroatom doping of activated carbon electrode materials is an effective method to improve the capacitive behavior of porous carbon electrode materials. ${ }^{38-42}$ In this work, N, P co-doped activated carbon prepared from the honeycomb as an electrode material for supercapacitors were tested in $3 \mathrm{M} \mathrm{KOH}$. N, P co-doped activated carbon showed an excellent electrochemical performance with good cycle stability, its specific capacity can reach $342.6 \mathrm{~F} \mathrm{~g}^{-1}$ at current density of $1.0 \mathrm{~A} \mathrm{~g}^{-1}$. It also shows excellent cycle performance, after 10000 charge and discharge cycle the specific capacitance is still maintained as the original $98.7 \%$. Moreover, we fabricate a symmetric supercapacitor device to further to study the electrochemical performance of $\mathrm{N}, \mathrm{P}$ codoped activated carbons. At a current density of $1.0 \mathrm{~A} \mathrm{~g}^{-1}$, the symmetric supercapacitor exhibits an excellent cycle performance that the specific capacitance maintains as the original 98.1\% after 10000 charge-discharge cycles. The symmetric supercapacitor gives a maximum energy density of $27.6 \mathrm{~W} \mathrm{~h} \mathrm{~kg}^{-1}$ at a power density of $398.4 \mathrm{~W} \mathrm{~kg}^{-1}$.

\section{Experimental sections}

\subsection{Preparation of the comb-derived activated carbon}

Honeycombs were cleaned with distilled water, dried at $80{ }^{\circ} \mathrm{C}$ for $24 \mathrm{~h}$. The dried honeycombs were recarbonized in a tubular furnace with a $\mathrm{N}_{2}$ flow at $400{ }^{\circ} \mathrm{C}$ for $2 \mathrm{~h}$ at a rate of $5{ }^{\circ} \mathrm{C} \mathrm{min}^{-1}$ (named as A-400). Subsequently, by chemical activation for improving specific surface area and benefiting to the formation of pore network, the precarbonized honeycombs were dipping in $\mathrm{KOH}$ aqueous solution as the chemical activating agent at a weight ratio of $1: 5$ and then stirred thoroughly for $7 \mathrm{~h}$ to ensure complete infiltration. And whereafter, the mixture was annealed at $900{ }^{\circ} \mathrm{C}$ for $1 \mathrm{~h}$ under a $\mathrm{N}_{2}$ atmosphere at a heating rate of $5{ }^{\circ} \mathrm{C} \min ^{-1}$ (named as HA-900). By contrast, without $\mathrm{KOH}$ activation, we also prepared ACs under the same under the same anneal temperature and conditions (named as A-900). Finally, hydrochloric acid ( $\mathrm{HCl}, 1 \mathrm{M})$ was used to wash the annealed sample repeatedly and the following we used plentiful distilled water to rinse for obtaining a neutral $\mathrm{pH}$. The final sample was gained by drying at $80{ }^{\circ} \mathrm{C}$ in air. Scheme 1 shows the transformation of honeycomb into porous activated carbons.

\subsection{Material characterization}

The crystal structure was measured by a Bruker D8 Advanced $\mathrm{X}$-ray diffractometer (Germany, CuK $\alpha$ radiation: $\lambda=1.5416 \AA$ ) to analyze X-ray diffraction (XRD) patterns. The functional groups and the chemical analysis of the samples were obtained by

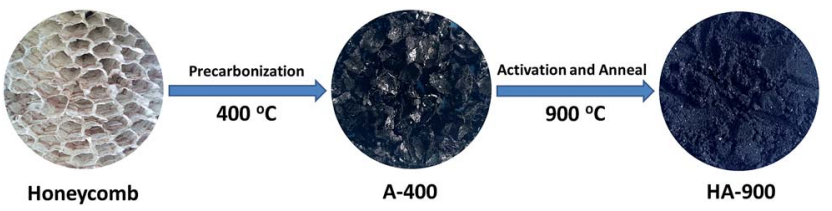

Scheme 1 Schematic illustration for the preparation of N, P co-doped activated carbons from honeycomb.

a Spectrum One (Perkin Elmer, USA) FTIR spectrometer and an Omicron NanoTechnology (ESCAL.ab250) X-ray photoelectron spectrometer (XPS), respectively. The morphologies of the prepared porous structure were characterized by a FESEM (Zeiss-Supra 55) and a HRTEM (Tecnai G2 F30 S-TWIN) with energy dispersive X-ray spectroscopy (EDS) mapping while the $\mathrm{N}_{2}$ adsorption-desorption isotherm and Brunauer-EmmettTeller (BET) of the samples were obtained at $77 \mathrm{~K}$ using an ASAP 2020 (Micromeritic USA) apparatus. Raman analysis of the samples was recorded using a DXRxi Raman spectrometer (Thermofisher, USA) with the laser power of $1.5 \mathrm{~mW}$ to minimize the heating effect. Thermal properties were determined using the PerkinElmer Pyris 1 thermogravimetric analyzer (TGA, USA) where the sample was heated to $1000{ }^{\circ} \mathrm{C}$ at a heating rate of $5{ }^{\circ} \mathrm{C} \min ^{-1}$ under a $\mathrm{N}_{2}$ flow.

\subsection{Electrochemical measurements}

For the electrochemical properties on above prepared electrodes, we made good use of the electrochemical measurements by cyclic voltammetry (CV), galvanostatic charge-discharge cycle (CDC) and electrochemical impedance spectroscopy (EIS), which were carried out respectively in a conventional threeelectrode configuration on a CHI 760E electrochemical workstation (Shanghai Chenhua, China) under the premise in a potential range of $-1.0-0.0 \mathrm{~V}$. Here, performance of the prepared electrodes was measured in $3 \mathrm{M} \mathrm{KOH}$ electrolyte, which equipped with a counter electrode (platinum), a reference electrode $(\mathrm{Hg} / \mathrm{HgO})$ and a working electrode just the above prepared N, P co-doped activated carbons electrode. The working electrodes were fabricated for the mixture with a mass ratio of $80: 15: 5$ of the dried $\mathrm{N}, \mathrm{P}$ co-doped activated carbons, conductive carbon (super $\mathrm{P}$ ) and polytetrafluoroethylene (PTFE) binder in $N$-methylpyrrolidinone (NMP) solvent dispersant therewith thoroughly stirring $0.5 \mathrm{~h}$ in the agate mortar to a paste, thereby uniformly coated onto a pre-cleaned nickel foam substrate with a square size of $1 \mathrm{~cm} \times 1 \mathrm{~cm}$. Then the electrode coated with above fabricated paste was annealed at $80{ }^{\circ} \mathrm{C}$ for $12 \mathrm{~h}$ in an oven. Until cooling to room temperature, we used a hydraulic equipment at $10 \mathrm{MPa}$ to press the final electrode to allow sufficient contact of the foam nickel with the active materials. The electrolyte was $3.0 \mathrm{M} \mathrm{KOH}$ solution. EIS plots reveal the response of the supercapacitor electrode observed with frequency range from $0.1 \mathrm{~Hz}$ to $10^{5} \mathrm{~Hz}$. The symmetric supercapacitors were assembled with $\mathrm{N}, \mathrm{P}$ co-doped activated carbon which can be fabricated into positive and negative electrode. For the symmetric supercapacitors, the method of preparation of the electrode was in keeping with the 
preparation of the working electrode in three-electrode system. The electrolyte used was also 3.0 $\mathrm{M} \mathrm{KOH}$ solution.

\section{Results and discussion}

In the case of pyrolysis, the decomposition of lignocellulose in honeycomb and the volatilization of some organic matter are carried out to obtain ACs with porous structure. Fig. S1a $\dagger$ is a FESEM image of the honeycomb carbonized material obtained after precarbonization at $400{ }^{\circ} \mathrm{C}$. Fig. 1a and b shows a SEM image of the HA-900 prepared from honeycomb carbonized material. The developed and irregular porous structure appeared in the HA-900 after the $\mathrm{KOH}$ activation. After increasing the magnification, we can clearly see the surface of the HA-900 inside the large holes with a large number of mesopores and micropores from Fig. 1b, so the material for the porous structure shows irregular block structures. It is taken for granted that the activation agent $(\mathrm{KOH})$ scattered into the layered porous structure can sufficiently facilitate activation. In contrast, A-400 and A-900 only have few pores (Fig. S1a and $b \dagger$ ).

As for the $\mathrm{KOH}$ activation, the carbon framework containing the various potassium compounds is partially etched by the carbon activation reaction between $\mathrm{KOH}$ and the feedstock, and the carbon lattice takes place with expanded so that the formed metal $\mathrm{K}$ can be effectively embedded in the carbon lattice of the carbon matrix while the production of $\mathrm{H}_{2} \mathrm{O}$ and $\mathrm{CO}_{2}$ also contributes to the formation of a well-formed pore network in the resulting product during the activating process. After

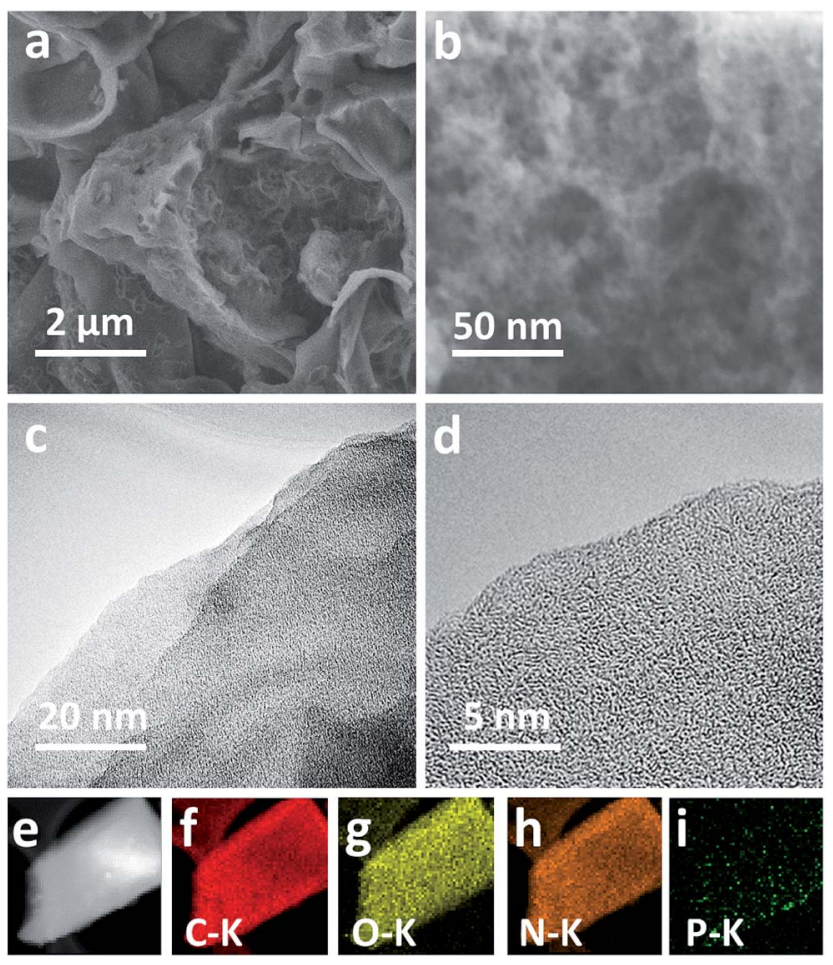

Fig. 1 ( $a$ and b) FESEM image of HA-900; ( $c$ and d) HRTEM image of HA-900; (e-i) STEM image (e) and EDS mapping of $\mathrm{C}-\mathrm{K}(\mathrm{f}), \mathrm{O}-\mathrm{K}(\mathrm{g})$, $\mathrm{N}-\mathrm{K}(\mathrm{h})$ and $\mathrm{P}-\mathrm{K}$ (i) from $\mathrm{HA}-900$. washing to remove the resulting potassium salts and excess $\mathrm{KOH}$ and meanwhile the pores that are present at the etched location cannot be restored to their previous construction, thus resulting in a large number of HA-900 with rich porosity.

As is depicted in Fig. 1c and d, HRTEM images of ACs surface conditions including the homologous five elemental mapping images of $\mathrm{C}, \mathrm{O}, \mathrm{N}$ and $\mathrm{P}$ produce almost similar morphologies. It is clear from the figure that there are many micropores and mesopores in HA-900. We can observe a typical amorphous carbon morphology, which can further prove the result of XRD pattern. By contrast, A-400 and A-900 merely exert the porous framework structure with only a few of blank spots (Fig. S1c and d $\dagger$ ).

For investigate characteristics of ACs, thermal properties which adopted to quantify the amount of ACs that occurred during the heating of honeycomb, were performed in Fig. S2. $\dagger$ Observing from the TGA curves, we can see that the weight loss temperature of the honeycomb is mainly from $200{ }^{\circ} \mathrm{C}$ to $900{ }^{\circ} \mathrm{C}$. Meanwhile, in view of the TGA analysis data, it is an optimum selection for $400{ }^{\circ} \mathrm{C}$ as the minimum pyrolysis temperature of honeycomb.

Fig. 2a exhibits the representative XRD patterns of samples. Two intense and broad diffraction peaks are evidently generated at approximately $2 \theta=23^{\circ}$ and $43^{\circ}$ of both of the A-400, A900 and HA-900 sample corresponding to the (002) and (100) diffraction patterns of amorphous carbon structure, respectively. The intensity at $2 \theta=26^{\circ}$ is the graphitic carbon structure. However, the sharp peaks at $26^{\circ}$ are not present in A-400 and it clearly
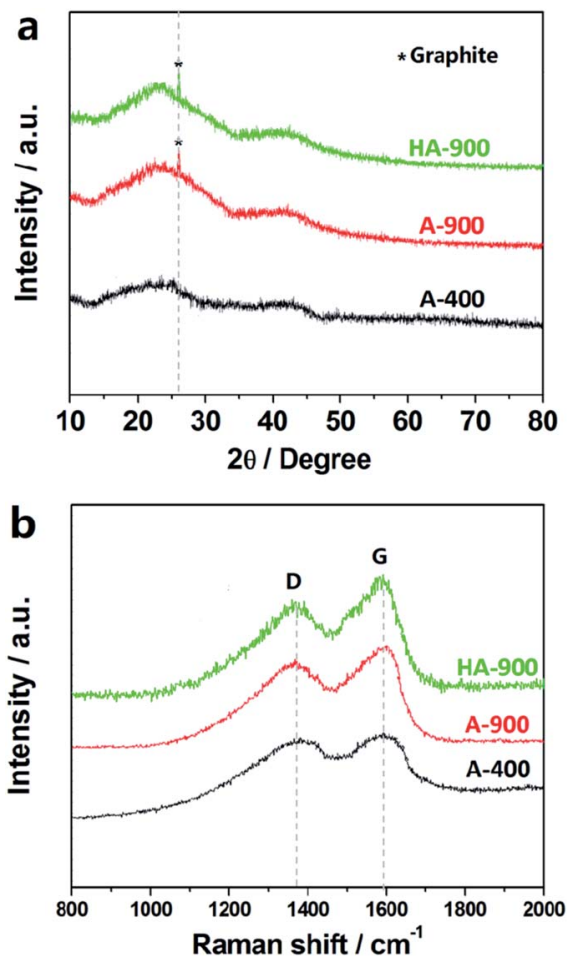

Fig. 2 (a) XRD pattern and (b) Raman spectra of the A-400, A-900 and HA-900 samples. 
explains that the graphitized carbon is formed only in A-900 and HA-900 samples.

Raman analysis is depicted in the Fig. 2b, the two prominent peaks shown in the Raman spectrum are located at $1342 \mathrm{~cm}^{-1}$ and $1587 \mathrm{~cm}^{-1}$, separately corresponding to D (defects and disorder)-band and $\mathrm{G}$ (graphitic)-band, which is attributed to $\mathrm{C}-\mathrm{C}$ graphitic lattice vibration mode. $I_{\mathrm{D}} / I_{\mathrm{G}}$ called as the ratio of intensities of "D-band" to "G-band" is calculated about 0.83 , which reflects its upper graphitization degree with large amount of structurally ordered graphite crystallites. The $I_{\mathrm{D}} / I_{\mathrm{G}}$ of A-400, A-900 and HA-900 was measured to be $0.99,0.93$ and 0.92 , respectively.

The FTIR analysis provides the qualitative information on the characteristic functional groups of the adsorbed materials in the surface of the porous carbons. Fig. 3a illustrates the FTIR spectra of the A-400, A-900 and HA-900 samples. The formation of the flexural vibration at $3435 \mathrm{~cm}^{-1}$ corresponding to $-\mathrm{O}-\mathrm{H}$ stretching are attributed to physical adsorption of water molecules or hydroxyl groups dominated. The two peaks that belong to asymmetric and symmetrical $\mathrm{C}-\mathrm{H}$ stretching are located at $2917 \mathrm{~cm}^{-1}$ and $2840 \mathrm{~cm}^{-1}$, respectively while the one of the $\mathrm{C}-\mathrm{H}$ group with the deformation mode is located at $1380 \mathrm{~cm}^{-1}$. The carbonyl group on the AC creates two kinds of weak peaks, separately designated as the stretching of $\mathrm{C}=\mathrm{O}$ of the one at $1700 \mathrm{~cm}^{-1}$ and the stretching mode of $\mathrm{C}=\mathrm{C}$ of another one at $1623 \mathrm{~cm}^{-1}$. From the FTIR analysis, the above structures demonstrate that A-400, A-900 and HA-900 samples are amorphous carbon with large amounts of oxygen-containing functional groups, the presence of which can provide additional pseudocapacitance for the material, good conductivity and more carboxyl and hydroxyl groups on ACs surfaces also indicate the excellent capacitance properties of the material.

In addition, the survey spectrum of honeycomb presented in Fig. $\mathrm{S} 3 \dagger$ indicates the presence of $\mathrm{C}, \mathrm{O}, \mathrm{N}$, and $\mathrm{P}$ elements. Fig. 3 b shows the XPS survey spectra of A-400, A-900 and HA-900
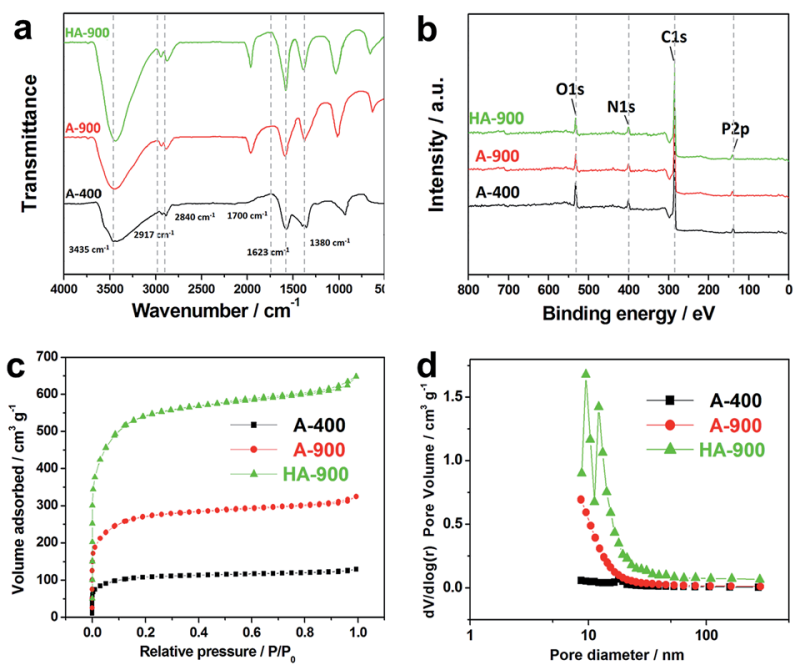

Fig. 3 (a) FTIR spectra, (b) survey spectrum (c) $\mathrm{N}_{2}$ adsorption/ desorption isotherms and (d) pore size distribution curves of the A-400, A-900 and HA-900 samples, respectively. samples exhibit the peaks corresponding to carbon, oxygen, nitrogen and phosphorus. The surface element composition of heteroatoms for A-400, A-900 and HA-900 samples including carbon, oxygen, nitrogen, phosphorus which are clearly detected at $284 \mathrm{eV}, 531 \mathrm{eV}, 406 \mathrm{eV}$, and $132 \mathrm{eV}$ respectively was analyzed by XPS. The amounts of different element on the surface of honeycomb, A-400, A-900 and HA-900 samples as calculated by XPS analysis are listed in Table S1. $\dagger$ Meanwhile the central spectra of resolved peaks at N1s, and P2p for A-400, A-900 and HA-900 samples are shown in Fig. S4. $\dagger$ The N1s XPS region spectra (peak fitting in the range of 395-408 eV) of the samples with different amounts of melamine addition are shown in Fig. S4a-c. $\dagger$ As shown in Fig. S3a-c, $\dagger$ there are four component peaks that are fit by the Lorentz equation, indicating the presence of three types of nitrogen functional groups in the sample pyrolyzed without melamine. The peaks at $398.5 \pm 0.1,400.1 \pm 0.1,401.2 \pm 0.1$ and $403.1 \pm 0.1 \mathrm{eV}$ cope with pyridinic nitrogen (N-6), pyrrolic/pyridone nitrogen (N-5), quaternary nitrogen $(\mathrm{N}-\mathrm{Q})$ and nitrogen oxides $(\mathrm{N}-\mathrm{X})$, respectively. ${ }^{4-47}$ As we discuss below, the relative content of N-5 and $\mathrm{N}-6$ increased with the higher addition of melamine into the raw materials, which is crucial to enhance the capacitive properties of ACs. According to Fig. S4d-f, $\dagger$ two peaks located at $134.48 \mathrm{eV}$ and $133.48 \mathrm{eV}$ are separated from P2p. It mainly comes into being the possible phosphorus-oxygen functional groups, called as various phosphates or $\mathrm{C}-\mathrm{PO}_{3}$ groups phosphorus, which can moderately restrict irreversible reaction during discharge/charge process. Therefore, it can be inferred that the persistence of phosphorus in ACs may contribute to the improvement of its electrochemical performances.

All curves of the nitrogen adsorption-desorption and pore size distributions for A-400, A-900 and HA-900 measured at $77 \mathrm{~K}$ are shown in Fig. $3 \mathrm{c}$ and d. It shows that the microporous structure of the $\mathrm{N}_{2}$ absorption increased greatly at $P / P_{0}<0.4$. And when $P / P_{0}>0.4$, there is an obvious hysteresis loop growing slowly for HA-900. The emergence of this phenomenon indicates its composition by a large number of micropores and mesopores in line with the combination of type I and IV isotherms. HA-900 consists of micropores, mesopores and large pores, with the mesopores dominant. The specific surface area and its pore volume of HA-900 are primarily as high as $1549.7 \mathrm{~m}^{2} \mathrm{~g}^{-1}$ and $0.81 \mathrm{~m}^{3} \mathrm{~g}^{-1}$, respectively. While A-900 and A400 have only $732.5 \mathrm{~m}^{2} \mathrm{~g}^{-1}$ and $103.6 \mathrm{~m}^{2} \mathrm{~g}^{-1}$ for the specific surface area with only $0.39 \mathrm{~cm}^{3} \mathrm{~g}^{-1}$ and 0.07 for its pore volume, respectively. Meanwhile, the pore size of HA-900 is also only centered at $3.13 \mathrm{~nm}$. The high specific surface area indicates that HA-900 has higher specific capacitance. Considering the comparative data above, it is easier to conclude that honeycomb precursors with $\mathrm{KOH}$ activation at high temperature can occur quickly and produce ultra-high specific surface area and appropriate mesopore size, which is beneficial for efficient charge storage. The pore-rich surface and narrower pore size distribution of ACs provide high ion accessibility through wider transport channels to micropores. So we expect the HA-900 would be the most promising electroactive material as for its largest specific surface area and optimized pore size for supercapacitors. 
To evaluate the electrochemical capacitance behavior of the A-900 and HA-900 supercapacitor electrodes prepared above, the $\mathrm{CV}$ analysis was performed to probe in $3 \mathrm{M} \mathrm{KOH}$ solution, and the voltage window was -1.0 to $0.0 \mathrm{~V}$. Both $\mathrm{CV}$ curves for HA-900 and A-900 at a scan rate from 5 to $100 \mathrm{mV} \mathrm{s}^{-1}$ are depicted in Fig. 4a and b respectively. And Fig. 4e also shows the comparison of CV curve for HA-900 and A-900 at a scanning speed of $10 \mathrm{mV} \mathrm{s}^{-1}$, indicating that HA-900 activated with $\mathrm{KOH}$ has a good capacitance performance. As the activated carbon is composed of micropores, mesopores and macropores in the channel structure, the electrolyte ions into the different size of pores need to overcome the different resistance. But electrolyte ions have slower diffusion rate in the micropores relative to the
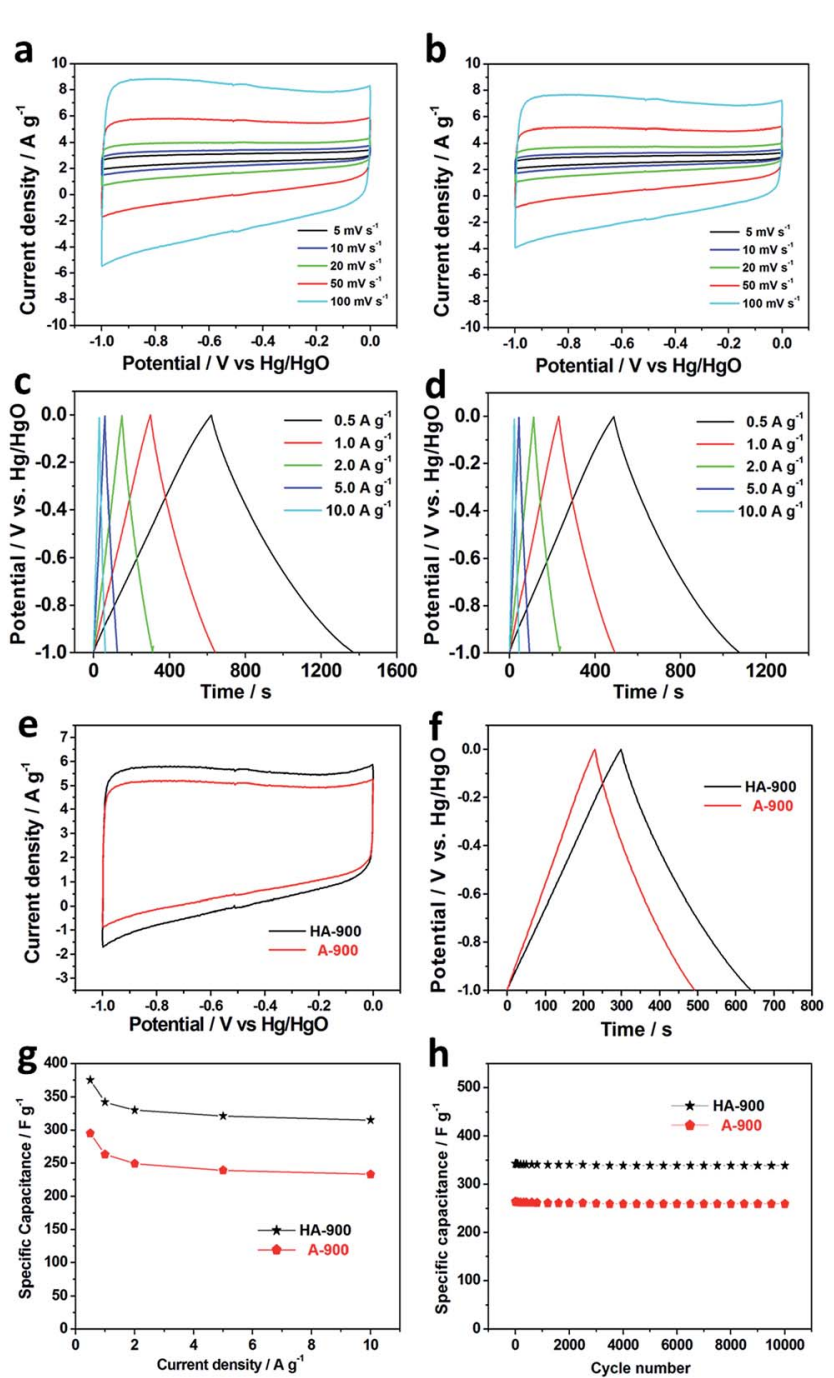

Fig. 4 CV curves of (a) HA-900 and (b) A-900 within the $-0.1-0.0 \mathrm{~V}$ range at a scan rate from 5 to $100 \mathrm{mV} \mathrm{s}^{-1}$ in $3 \mathrm{M} \mathrm{KOH}$; the galvanostatic charge-discharge curves for (c) HA-900 and (d) A-900 at various current densities of $0.5-10.0 \mathrm{~A} \mathrm{~g}^{-1}$; (e) CV curves of a HA-900 and A900 at a scan rate of $10 \mathrm{mV} \mathrm{s}^{-1}$ in $3 \mathrm{M} \mathrm{KOH}$; (f) charge-discharge curves of HA-900 and A-900 at a current density of $1 \mathrm{~A} \mathrm{~g}^{-1}$ in $3 \mathrm{M}$ $\mathrm{KOH}$; (g) variations of specific capacitance against current density of $\mathrm{HA}-900$ and A-900, and (h) cyclic performance of the HA-900 and A900 electrode measured at a constant current density of $1.0 \mathrm{~A} \mathrm{~g}^{-1}$. large so that the response current needs to produce a relaxation time. Therefore, EDLC cyclic voltammetry curves show a quasirectangular shape, which indicates that the material with porous structure is stable. At the same time, it is further observed that the response current and the quasi-rectangular area of the CV curve for the HA-900 electrode contrasted with A-900 are much larger. In addition, in the range of the scan voltage, there is a slight polarization at the positive and negative potentials which represent the complex reversible redox reaction happened on the ACs surface. The presence of polarization phenomena is also attributed to the multiple functional groups on the ACs surface.

Galvanostatic charge-discharge method is commonly used for studying the capacitance performance of electrode materials. Fig. 4c and d shows galvanostatic charge-discharge curves for HA-900 and A-900 with a condition of $3 \mathrm{M} \mathrm{KOH}$ electrolyte at various current densities of $0.5-10.0 \mathrm{~A} \mathrm{~g}^{-1}$, respectively. And Fig. $4 \mathrm{f}$ also shows the comparison of the galvanostatic chargedischarge curves behavior of HA-900 and A-900 electrodes at $1 \mathrm{~A} \mathrm{~g}^{-1}$ current density, concluding that the charging and discharging time of HA-900 is significantly longer than that of A-900. The galvanostatic charge-discharge curves of ACs exhibit a good linearity and a relatively symmetrical triangular shape, indicating that ACs have good electrochemical behavior with excellent reversibility.

According to the following formula, we can calculate the specific capacitance of:

$$
C=Q /(m \times \Delta V)=I \times t_{\text {discharge }} /(m \times \Delta V)
$$

where $m$ is the weight of the electrode material $I$ is the discharge current, $t_{\text {discharge }}$ is discharge time, $\Delta V$ is the potential drop during discharge. From the Fig. $4 \mathrm{~g}$, the maximum specific capacitance of HA-900 at the current density of $0.5 \mathrm{~A} \mathrm{~g}^{-1}$ is about $375 \mathrm{~F} \mathrm{~g}^{-1}$ while A-900 has $295 \mathrm{~F} \mathrm{~g}^{-1}$, both of which are derived from the discharging curves, indicating that the specific capacitance of the HA-900 electrode compared with the one without activation is much higher and both of the two samples exhibit good rate capability. When the current density is increased to $10 \mathrm{~A} \mathrm{~g}^{-1}$, the ions do not have enough time to diffuse into all the pore structures of the electrode material, resulting in a decrease in the capacitance as the increase of the current density. When the current density increases to $10.0 \mathrm{~A} \mathrm{~g}^{-1}$, the capacitance of HA-900 is still retained $84 \%$, which demonstrates that the HA-900 has a fast charge and discharge capability and excellent discharge rate performance due to the high specific surface area, the large pore volume and its nanoporous structure of the HA-900. The micropores favorably can form a dense double layer capacitance and the mesoporous and macroporous structures can facilitate the rapid diffusion and transfer of electrolyte ions in the pores while A900 with smaller pores is difficult to form a dense double layer capacitance. And also the surface oxygen-containing functional groups of the active components are likely to exist part of the pseudocapacitance. Due to the synergistic effect of the presence of various heteroatoms such as $\mathrm{C}, \mathrm{N}, \mathrm{O}, \mathrm{P}$, etc., the carbon material prepared not only exhibits larger redox 
pseudocapacitance, but also heteroatom doping is beneficial to suppress an irreversible change of the oxygen-containing functional groups on ACs surface during the charging and discharging process. It also shows that the reasonable porosity generated by $\mathrm{KOH}$ activation of ACs is beneficial to the formation of dense double electric layer capacitance and rapid transmission in $\mathrm{KOH}$ electrolyte, which can significantly improve the capacitance behavior.

Another important performance of supercapacitors is electrochemical stability. To check the actual expandability of these electrodes, HA-900 and A-900 electrodes were used a current density of $1.0 \mathrm{~A} \mathrm{~g}^{-1}$ with a $3 \mathrm{M} \mathrm{KOH}$ electrolyte to perform 10000 cycles of the electrochemical stability, as shown in the Fig. 4h. Until 10000 cycles, the capacitance of HA-900 and A-900 electrodes remain stable afterward and the final specific capacitance retention rate are almost about $98.7 \%$ and $98.3 \%$, respectively. In order to measure the morphology of the electrode materials after long charge-discharge cycles, we characterized the samples by SEM. From Fig. S5, $\dagger$ we can see that few changes of HA-900 and A-900 emerged after 10000 chargedischarge cycles.

The research of the ion transport mechanism and further demonstration of the performance for HA-900 and A-900 electrodes respectively were testified by electrochemical impedance spectroscopy. The EIS analysis above carried out with the frequency range from $10 \mathrm{mHz}$ to $10^{5} \mathrm{~Hz}$ shows the Nyquist plot with a small semicircle and a nearly straight line at the high/low frequency region respectively in Fig. S6, $\uparrow$ intuitively indicating porous carbon electrodes with a distinct capacitive property. From data analysis of the high frequency region, just a small semicircle is generated relevant to charge transport phenomena (RCT) during the testing process at the electrode-electrolyte interface where the electrolyte ions can rapidly diffuse to the outer surface of the activated carbon electrode and the inner surface of the macroporous or mesoporous, thus concluding that there is a existence of Faraday impedance of charge transfer. In the meantime, the ohmic resistance (RS) was estimated which can be deemed that the internal resistance of the carbon material is very small (less than $0.2 \Omega$ ), indicating that the carbon material is well conductive. It also manifests that the kinetics process of the electrochemical system is very fast and the ion transport plays a leading role, which is the diffusion transmission state of the electrolyte ions in the channel. Viewing from the low frequency region, the inclined portion of the impedance rises sharply (slope close to $90^{\circ}$ ). The straight line shows that ACs have pure double electric layer capacitance behavior and the characteristics of electrolyte ions fast transfer. The fundamental reason for this capacitive behavior is that the palm kernel shell-based porous activated carbon has a porous structure with low resistance and suitable ion diffusion transport.

To further evaluate the $\mathrm{N}, \mathrm{P}$ co-doped activated carbon electrode for practical application, we fabricated a symmetric supercapacitor based on the same two HA-900 electrodes in $3 \mathrm{M}$ $\mathrm{KOH}$ electrolyte solution. Fig. 5a exhibits CV curves of HA-900// HA-900 symmetric supercapacitor at different potential windows from 1.0 to $1.8 \mathrm{~V}$ at a scan rate of $10 \mathrm{mV} \mathrm{s}^{-1}$. From the
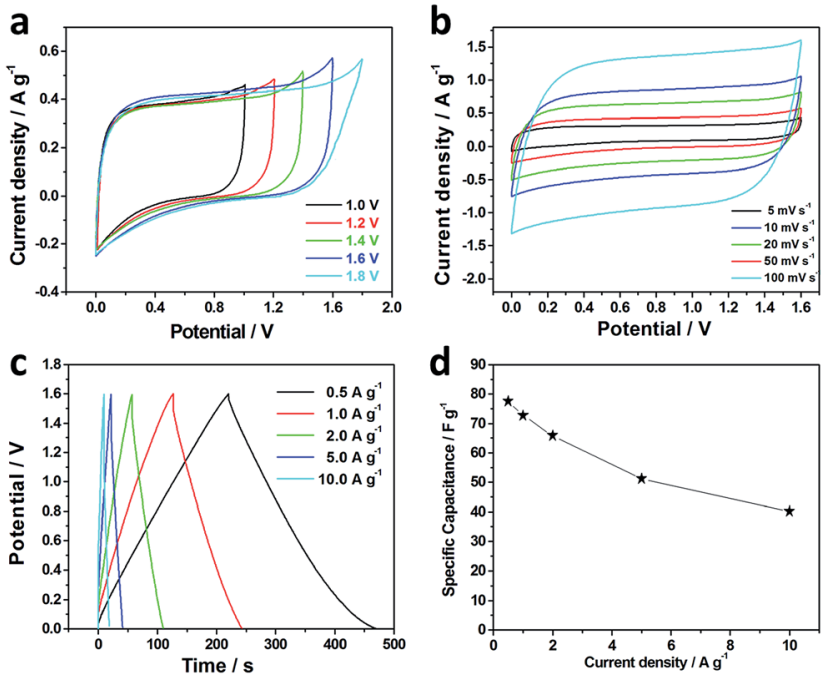

Fig. 5 Electrochemical characteristics of HA-900//HA-900 symmetric supercapacitor in $3 \mathrm{M} \mathrm{KOH}$ aqueous electrolyte. (a) $\mathrm{CV}$ curves in different voltage windows at $10 \mathrm{mV} \mathrm{s}^{-1}$; (b) CV curves at different scan rates $\left(5-100 \mathrm{mV} \mathrm{s}^{-1}\right.$ ). (c) Galvanostatic chargedischarge curves for various current densities $\left(0.5-10.0 \mathrm{~A} \mathrm{~g}^{-1}\right)$; (d) the relation between specific capacitance and current density.

figure, we can see that the as-fabricated symmetric supercapacitor can be reversibly cycled within the voltage window of 0-1.8 V. However, the current curve increases sharply in high voltage at the operating voltage of $1.8 \mathrm{~V}$. Therefore, we test the performance of the HA-900//HA-900 symmetric supercapacitor under the wide potential window of $1.6 \mathrm{~V}$. Fig. 5b shows the CV curves of the symmetric supercapacitor at different scan rates from 5 to $100 \mathrm{mV} \mathrm{s}^{-1}$. From the $\mathrm{CV}$ curves, the mirror image-like behavior is obvious, which can manifest the good electrochemical performance of the HA-900//HA-900 symmetric supercapacitor. At a higher scan rate of $100 \mathrm{mV} \mathrm{s}^{-1}$, the shape of the $\mathrm{CV}$ curve remains rectangularity, which can manifest that the device has good electrochemical reversibility. We carried out galvanostatic charge-discharge cycles to further quantitatively evaluate the rate performances and accurately determine the specific capacitances for various current densities $(0.5$ to $10.0 \mathrm{~A} \mathrm{~g}^{-1}$ ). As shown in Fig. 5c, all charge-discharge curves of the HA-900//HA-900 symmetric supercapacitor are linear and symmetrical at various current densities, which can clarify that the electrode materials exhibit excellent Coulomb efficiency. The specific capacitances are calculated from the discharge curves of the galvanostatic profiles (Fig. 5d). HA-900//HA-900 symmetric supercapacitor exhibits a specific capacitance of $77.5 \mathrm{~F} \mathrm{~g}^{-1}$ at $0.5 \mathrm{~A} \mathrm{~g}^{-1}$ and $40.1 \mathrm{~F} \mathrm{~g}^{-1}$ at $10.0 \mathrm{~A} \mathrm{~g}^{-1}$ (retention of $51.7 \%$ ), displaying good rate capability, superior ion-transport properties and excellent performance of the HA-900//HA-900 symmetric supercapacitor.

Fig. 6a shows the cyclic stability of the HA-900//HA-900 symmetric supercapacitor device at a current density of $1 \mathrm{~A} \mathrm{~g}^{-1}$ up to 10000 cycles. After 10000 cycles, $98.1 \%$ of the initial specific capacitance is maintained, which exhibit a good cycle stability. 

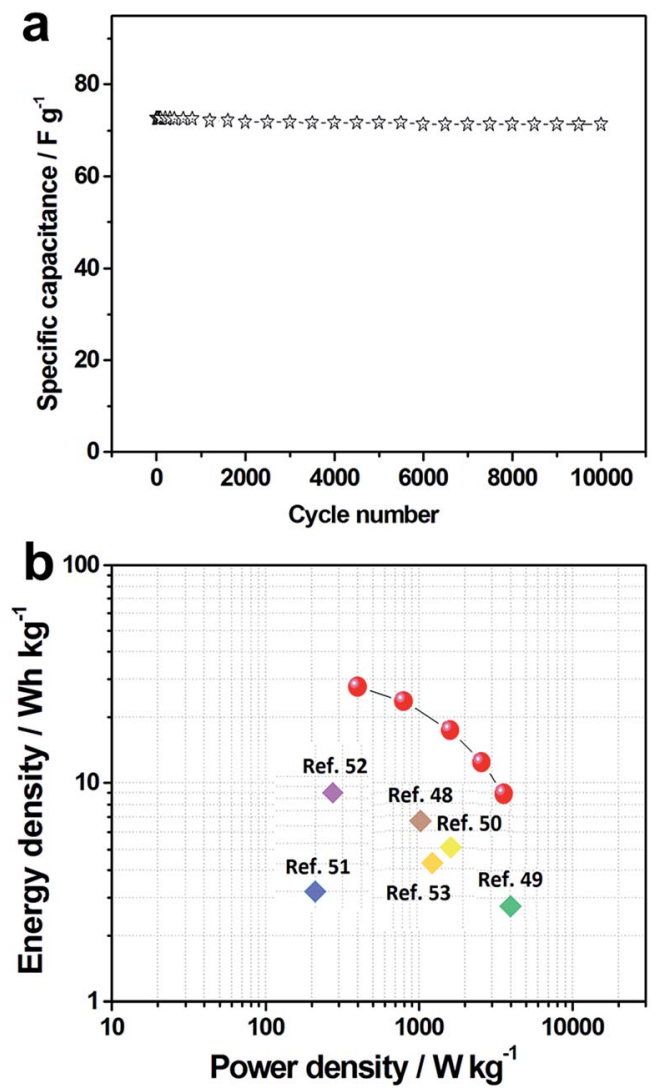

Fig. 6 (a) Cycle stability test studies of HA-900//HA-900 symmetric supercapacitor at $1 \mathrm{~A} \mathrm{~g}^{-1}$ over the 10000 cycles; (b) Ragone plot of the HA-900//HA-900 symmetric supercapacitor device.

The energy and power density of the HA-900//HA-900 symmetric supercapacitor can be calculated from the following equations:

$$
\begin{gathered}
E=C \times(\Delta V)^{2} / 7.2 \\
P=3600 \times E / \Delta t
\end{gathered}
$$

where, $E\left(\mathrm{~W} \mathrm{~h} \mathrm{~kg}^{-1}\right), P\left(\mathrm{~W} \mathrm{~kg}^{-1}\right), C\left(\mathrm{~F} \mathrm{~g}^{-1}\right)$, and $\Delta t(\mathrm{~s})$ are the energy density, power density, specific capacitance, and discharge time, respectively. Fig. $6 \mathrm{~b}$ shows the Ragone plot of the energy density vs. power density of the HA-900//HA-900 symmetric supercapacitor device. Hence, the calculated maximum energy value is $27.6 \mathrm{~W} \mathrm{~h} \mathrm{~kg}^{-1}$ at a power density of $398.4 \mathrm{~W} \mathrm{~kg}^{-1}$. What's more, the maximum energy density of the HA-900//HA-900 symmetric supercapacitor precede that of previously reported carbon-based supercapacitors. ${ }^{48-53}$

\section{Conclusions}

In summary, N, P co-doped activated carbons have been successfully prepared from honeycomb. The N, P co-doped activated carbons has large numbers of mesopores and innovative surface-interface features, which play an important role in the electrolyte access, and ion intercalation-extraction processes. The electrochemical tests of $\mathrm{N}, \mathrm{P}$ co-doped activated carbons clearly show that the obtained materials could be employed as supercapacitor electrode materials. The as-prepared materials also show great potential in the fields of other energy storage devices. Further investigation is expected to explore other potential application.

\section{Conflicts of interest}

There are no conflicts to declare.

\section{Acknowledgements}

This work was supported by the Program for New Century Excellent Talents of the University in China (NCET-13-0645) and the National Natural Science Foundation of China (NSFC21671170 and 21673203), Program for Innovative Research Team (in Science and Technology) in University of Henan Province (14IRTSTHN004), Innovation Scientists and Technicians Troop Construction Projects of Henan Province (164200510018), the Six Talent Plan (2015-XCL-030), Qinglan Project and Excellent Doctoral Dissertation of Yangzhou University. We also acknowledge the Priority Academic Program Development of Jiangsu Higher Education Institutions and the technical support we received at the Testing Center of Yangzhou University.

\section{References}

1 C. Liu, F. Li, L. Ma and H. Cheng, Adv. Mater., 2010, 22, E28.

2 S. Chu and A. Majumdar, Nature, 2012, 488, 294.

3 D. Lindley, Nature, 2010, 463, 18.

4 P. Simon and Y. Gogotsi, Nat. Mater., 2008, 7, 845.

5 J. Chmiola, C. Largeot, P.-L. Taberna, P. Simon and Y. Gogotsi, Science, 2010, 328, 480.

6 P. Simon, Y. Gogotsi and B. Dunn, Science, 2014, 343, 1210.

7 M. Winter and R. J. Brodd, Chem. Rev., 2004, 104, 4245.

8 H. Zhang, Y. Wang, C. Liu and H. Jiang, J. Alloys Compd., 2012, 517, 1 .

9 Q. Wu, M. Chen, K. Chen, S. Wang, C. Wang and G. Diao, J. Mater. Sci., 2016, 51, 1572.

10 Y. Zhang, Y. Wang, T. Chen, W. Lai, H. Pang and W. Huang, Chem. Soc. Rev., 2015, 44, 7484.

11 B.-X. Dong, J. Ge, Y.-L. Teng, J.-J. Gao and L. Song, J. Mater. Chem. A, 2015, 3, 905.

12 M. Chen, W. Li, X. Shen and G. Diao, ACS Appl. Mater. Interfaces, 2014, 6, 4514.

13 M. Wang, J. Han, H. Xiong, R. Guo and Y. Yin, ACS Appl. Mater. Interfaces, 2015, 7, 6909.

14 J. Tong, H. Zhang, J. Gu, L. Li, C. Ma, J. Zhao and C. Wang, J. Mater. Sci., 2016, 51, 1966.

15 J. Daubert, N. Lewi, H. Gotsch, J. Mundy, D. Monroe, E. Dickey, M. Losego and G. Parson, Chem. Mater., 2015, 27, 6524.

16 W.-J. Lu, S.-Z. Huang, L. Miao, M.-X. Liu, D.-Z. Zhu, L.-C. Li, H. Duan, Z.-J. Xu and L.-H. Gan, Chin. Chem. Lett., 2017, 28, 1324. 
17 L. Miao, D. Zhu, Y. Zhao, M. Liu, H. Duan, W. Xiong, Q. Zhu, L. Li, Y. Lv and L. Gan, Microporous Mesoporous Mater., 2017, 253, 1.

18 M. Liu, X. Ma, L. Gan, Z. Xu, D. Zhu and L. Chen, J. Mater. Chem. A, 2014, 2, 17107.

19 P. Cheng, T. Li, H. Yu, L. Zhi, Z. Liu and Z. Lei, J. Phys. Chem. C, 2016, 120, 2079.

20 Z. Li, Z. Xu, X. Tan, H. Wang, C. M. Holt, T. Stephenson, B. C. Olsen and D. Mitlin, Energy Environ. Sci., 2013, 6, 871.

21 J. Yan, Q. Wang, T. Wei and Z. Fan, Adv. Energy Mater., 2014, 4, 1300816.

22 X. Li, W. Xing, S. Zhuo, J. Zhou, F. Li, S.-Z. Qiao and G.-Q. Lu, Bioresour. Technol., 2011, 102, 1118.

23 A. Olejniczak, M. Lezanska, J. Wloch, A. Kucinska and J. P. Lukaszewicz, J. Mater. Chem. A, 2013, 1, 8961.

24 S. A. Wohlgemuth, R. J. White, M. G. Willinger, M. M. Titirici and M. Antonietti, Green Chem., 2012, 14, 1515.

25 S. A. Wohlgemuth, F. Vilela, M.-M. Titirici and M. Antonietti, Green Chem., 2012, 14, 741.

26 L. Sun, C. G. Tian, M. T. Li, X. Y. Meng, L. Wang, J. Yin and H. G. Fu, J. Mater. Chem. A, 2013, 1, 6462.

27 M. Chen, C. Yu, S. H. Liu, X. M. Fan, C. T. Zhao, X. Zhang and J. S. Qiu, Nanoscale, 2015, 7, 1791.

28 W. Da-Wei, Z. Qingcong, Z. Guangmin, Y. Lichang, L. Feng, C. Hui-Ming, I. R. Gentle and L. Gao Qing Max, J. Mater. Chem. A, 2013, 1, 9382-9394.

29 Y. M. Li, X. Y. Wu, J. Z. Yu, Y. S. Wang, Y. S. Hu, H. Li, L. Q. Chen and X. J. Huang, J. Mater. Chem. A, 2015, 3, 71.

30 N. Sun, H. Liu and B. Xu, J. Mater. Chem. A, 2015, 3, 20560.

31 Y. Li, N. Yu, P. Yan, Y. Li, X. Zhou, S. Chen, G. Wang, T. Wei and Z. Fan, J. Power Sources, 2015, 300, 309.

32 J. Wang, L. Shen, Y. Xu, H. Dou and X. Zhang, New J. Chem., 2015, 39, 9497.

33 W. Wang, H. Quan, W. Gao, R. Zou, D. Chen, Y. Dong and L. Guo, RSC Adv., 2017, 7, 16678.

34 Y. Zhao, W. Ran, J. He, Y. Song, C. Zhang, D.-B. Xiong, F. Gao, J. Wu and Y. Xia, ACS Appl. Mater. Interfaces, 2015, 7, 1132.

35 J. Hou, C. Cao, F. Idrees and X. Ma, ACS Nano, 2015, 9, 2556.
36 M. Zhu, J. Lan, X. Zhang, G. Sui and X. Yang, New J. Chem., 2017, 41, 4281.

37 M. Sivachidambaram, J. J. Vijaya, L. J. Kennedy, R. Jothiramalingam, H. A. Al-Lohedan, M. A. Munusamy, E. Elanthamilan and J. P. Merlin, New J. Chem., 2017, 41, 3939.

38 C. K. Kim, I. T. Choi, S. H. Kang and H. K. Kim, RSC Adv., 2017, 7, 35565.

39 X. Wu, Z. Tian, L. Hu, S. Huang and J. Cai, RSC Adv., 2017, 7, 32795.

40 X. Li, S. Ding, X. Xiao, J. Shao, J. Wei, H. Pang and Y. Yu, J. Mater. Chem. A, 2017, 5, 12774.

41 X. Zhou, P. Wang, Y. Zhang, L. Wang, L. Zhang, L. Zhang, L. Xu and L. Liu, J. Mater. Chem. A, 2017, 5, 12958.

42 Y. Xu, S. Wu, S. Ren, J. Ji, Y. Yue and J. Shen, $R S C A d v .$, 2017, 7, 32496.

43 T. Lin, I. W. Chen, F. Liu, C. Yang, H. Bi, F. Xu and F. Huang, Science, 2015, 350, 1508.

44 F. Lai, Y. E. Miao, L. Zuo, H. Lu, Y. Huang and T. Liu, Small, 2016, 12, 3235.

45 Y. Tan, C. Xu, G. Chen, Z. Liu, M. Ma, Q. Xie, N. Zheng and S. Yao, ACS Appl. Mater. Interfaces, 2013, 5, 2241.

46 X. Wei, S. Wan and S. Gao, Nano Energy, 2016, 28, 206.

47 L. F. Chen, Z. H. Huang, H. W. Liang, Q. F. Guan and S. H. Yu, Adv. Mater., 2013, 25, 4746.

48 Y. Li, C. Chen, T. Gao, D. Zhang, X. Huang, Y. Pan, K. Ye, K. Cheng, D. Cao and G. Wang, Chem.-Eur. J., 2016, 22, 16863.

49 L. Sun, C. Tian, Y. Fu, Y. Yang, J. Yin, L. Wang and H. Fu, Chem.-Eur. J., 2014, 20, 564.

50 Q. Hao, X. Xia, W. Lei, W. Wang and J. Qiu, Carbon, 2015, 81, 552.

51 D. H. Seo, S. Yick, D. Su, G. Wang, Z. J. Han and K. Ostrikov, Carbon, 2015, 91, 386.

52 Z. Hu, S. Li, P. Cheng, W. Yu, R. Li, X. Shao, W. Lin and D. Yuan, J. Mater. Sci., 2016, 51, 2627.

53 Y. Huang, Y. Liu, G. Zhao and J. Y. Chen, J. Mater. Sci., 2017, 52, 478. 